\title{
La relación entre latitudinarismo, escepticismo, tolerancia y protestantismo en la obra de John Locke
}

\author{
The relation between latitudinarianism, \\ skepticism, toleration and protestantism \\ in John Locke's work
}

\author{
JOAN SEVERO CHUMBITA \\ FFyL UBA/Idaes-UNSAM/CONICET
}

Recibido: 02/10/14 Aceptado: 29/01/15

\begin{abstract}
RESUMEN:
Este trabajo tiene por objeto analizar la articulación entre la afirmación del carácter racional de la fe, esto es, su dimensión latitudinaria, el escepticismo epistemológico, y su derivación práctica en un concepto de tolerancia restringido al interior del protestantismo. Se subrayará, en este sentido, el carácter estratégico de la articulación entre racionalidad de la fe y escepticismo, en cuanto permite apelar a la ignorancia con vistas a la tolerancia, sin por ello dejar de sostener la interpretación protestante del cristianismo, en detrimento de la interpretación católica.

PALABRAS CLAVE:

LOCKE - LATITUDINARISMO - ESCEPTICISMO - TOLERANCIA - PROTESTANTISMO

ABSTRACT:

This paper aims to analyze the articulation between faith rationality assertion, i.e. its latitudinarian aspect, its epistemological skepticism, and its practical implication in a restricted concept of tolerance within Protestantism. In this regard, we will emphasize the strategic feature of the link between faith rationality and skepticism, as it allows
\end{abstract}

(C) Contrastes. Revista Internacional de Filosofia, vol. XXI-Noº (2016), pp. 63-78. ISSN: 1136-4076

Departamento de Filosofía, Universidad de Málaga, Facultad de Filosofía y Letras Campus de Teatinos, E-29071 Málaga (España) 
appealing to ignorance towards tolerance, without dropping the Protestant interpretation of Christianity, to the detriment of Catholic interpretation.

\section{KEYWORDS:}

LOCKE - LATITUDINARIANISM - SKEPTICISM - TOLERATION PROTESTANTISM

Y pienso que igualmente se apartan de la verdad, quienes, refugiándose en los contrarios extremos, o afirman que hay una ley innata, o niegan que hay una ley cognoscible por la luz natural, es decir, sin el socorro de una revelación positiva.

John Locke ${ }^{1}$

No puede haber evidencia de que una revelación tradicional proceda de Dios (en los términos en que la recibimos y en el sentido en que la entendemos) que sea tan clara y tan segura como la evidencia de los principios de la razón.

John Locke ${ }^{2}$

Tal cuerpo de ética, provisto por la ley de naturaleza, a partir de principios de la razón, y enseñando a todos los deberes de la vida; pienso que nadie estaría dispuesto a sostener que el mundo lo tuviera con anterioridad al tiempo de Nuestro Salvador.

John Locke ${ }^{3}$

La formulación del contenido de una ley de naturaleza universal válida para todos los hombres deviene mucho más compleja cuando la estricta posición racionalista ha sido abandonada, y se vuelve poco menos que imposible una vez que se reconoce el valor de la tradición, la fe y las costumbres en la determinación de ese contenido. James Hancey ${ }^{4}$

[...] a ese hábito de invocar la fe en oposición a la razón se deben, me parece, en buena medida, todos esos absurdos de que están tan llenas casi todas las religiones que se han posesionado de la humanidad y que la dividen.

John Locke ${ }^{5}$

1 Essay, I, IV, §13.

2 Essay, IV, XVIII, §10.

3 R, 1977: 227.

4 Hancey, 1976: 451.

5 Essay, IV, XVIII, §11. 
[...] la razón es el juez competente; y aunque la revelación, al estar de acuerdo, pueda confirmar sus decisiones, no puede, sin embargo, en tales casos, invalidar sus decretos.

John Locke ${ }^{6}$

BASÁNDOSE TANTO EN LA CRÍTICA A LA TRADICIÓN FILOSÓFICA por no haber sido capaZ de producir una demostración de la moral al igual que de las matemáticas $\left(R^{7}\right.$, 1977: 233, 227-230, Gough, 1964: 7; Hancey, 1976: 443 ${ }^{8}$ ), en la idea de que existen proposiciones no contrarias a la razón, pero «por encima» de ella -al menos en su uso natural, empírico-demostrativo- (Essay ${ }^{9}$, IV, XVII, §23), así como en el carácter limitado de las facultades cognitivas del hombre (Locke, Essay, IV, XVI, §4; véase también IV, III, §1; I, I, §4-6; Ashcraft, 1969a: 209210), Locke va a establecer un escepticismo suficiente como para afirmar la necesidad de cierta tolerancia religiosa. La crítica epistemológica se convierte de este modo en premisa de una propuesta ético-política.

En efecto, especialmente en materia de fe, Locke señala que es preciso mostrarse tolerante a fin de mantener una convivencia pacífica (Shapiro, 1968: 40). Existiendo, como es el caso, tal diversidad de creencias y prácticas religiosas en el mundo $\left(E L N^{10}, 2007\right.$ : 16; véase también 76-77; $R$, 1977: 207-208, 212-213; $L^{11}$, 1999: 146; Ashcraft, 1968: 908), resulta fundamental evitar la imposición violenta de una determinada interpretación, particularmente cuando nuestras capacidades cognitivas nunca eliminan la posibilidad de error.

Bien haremos en tener conmiseración de nuestra ignorancia mutua, y tratar de disiparla por todos los medios mansos y equitativos que se pueden emplear para informar debidamente, y no maltratar instantáneamente a los otros como gente obstinada y perversa, sólo porque no quieren renunciar a sus propios opiniones y recibir las nuestras, o por lo menos aquellas que pretendemos imponerles, cuando es más probable que no seamos nosotros menos obstinados que ellos en no querer recibir ninguna de las suyas (Essay, IV, XVI, §4; véase también IV, III, §4).

6 Essay, IV, XVIII, §6.

7 The Reasonableness of Christianity. Usaremos en todos los casos la edición castellana, traducida por Leandro González Puertas.

8 Hobbes ya había hecho este mismo reproche a la tradición filosófica: «ni Platón, ni ningún otro filósofo, hasta ahora ha puesto en orden y ha probado suficientemente, o de manera probable, todos los teoremas de doctrina moral» (Hobbes, 1999: XXXI, 311).

9 Essay Concerning Human Understanding. Usaremos en todos los casos la edición castellana, traducida por Carlos Mellizo.

10 Essays on the Law of Nature. Usaremos en todos los casos la edición castellana, traducida por Carlos Mellizo.

11 A Letter Concerning Toleration. Usaremos en todos los casos la edición castellana, traducida por L. Prieto Sanchís y J. Betegón Carrillo. 
El hombre percibe desde una perspectiva situada, con un entendimiento limitado (EMO ${ }^{12}$, 1991: 62; véase Ashcraft, 1969: 195). Por tanto, no puede pretender obtener un conocimiento absoluto, como el resultante, por ejemplo, de ver todas las cosas en Dios $\left(R N B^{13}, 1991 b: 57^{14}, 81,83,79,55^{15}\right)$. Contra la tesis de Malebranche, Locke argumentará que carecería de sentido dotar al hombre de facultades sensibles para luego sostener que el conocimiento humano surge de una percepción directa en el entendimiento divino (Locke, 1991a: $85^{16}$ ). Por otra parte, si fuera este el caso, tampoco sería sería posible que se cometieran la infinidad de errores de que somos pasibles por nuestras facultades limitadas y falibles de conocimiento (véase Wood, 1983: 6).

Nuestra ignorancia es muy grande [ ] la cual, siendo infinitamente más grande que nuestro conocimiento, podrá servir para acallar las disputas y para fomentar los

12 An Examination of P. Malebranche's Opinion of Seeing All Things in God. Usaremos en todos los casos la edición castellana, traducida por José Antonio Robles y Carmen Silva.

13 Remarks upon some of Mr. Norris's books. Usaremos aquí en todos los casos la edición castellana, traducida por José Antonio Robles y Carmen Silva, titulada: «Observaciones sobre algunos de los libros del Sr. Norris en los que asevera la opinión del Padre Malebranche de ver todas las cosas en Dios».

14 «Por lo tanto, no estoy convencido de la verdad de lo que sigue, que «no vemos ninguna cosa sino por el conocimiento natural que tenemos de Dios», la que me parece una forma muy contraria de argüir a la que usa el apóstol, cuando dice que «las cosas invisibles de Dios se ven por las cosas visibles que ha hecho». Pues me parece una forma muy contraria de argüir decir que vemos al Creador en o por las criaturas y que vemos las criaturas en el Creador. El apóstol comienza nuestro conocimiento en las criaturas, lo que nos conduce al conocimiento de Dios, si hacemos uso de nuestra razón; nuestro autor comienza nuestro conocimiento en Dios y eso nos conduce a las criaturas» (Locke, 1991a: 57).

15 «Hay quienes piensan que han dado una explicación de la naturaleza de las ideas al decirnos «las vemos en Dios» como si entendiésemos lo que son las ideas en el entendimiento de Dios mejor que lo que son en nuestro propio entendimiento» (Locke, 1991b: 83). «[...] «entonces, las ideas o perfecciones inteligibles que están en Dios, que nos representan lo que está fuera de Dios, son absolutamente necesarias e inmutables». Concedo de inmediato que son necesarias e inmutables las perfecciones que están en Dios; pero no puedo concebir que las ideas que les son inteligibles a Dios o que están en el entendimiento de Dios (pues así debemos hablar de él mientras le concibamos a la manera de los hombres), podamos verlas o que las perfecciones que están en Dios nos representen las esencias de las cosas que están fuera de Dios. La esencia de la materia, hasta donde puedo verla, es extensión, solidez, divisibilidad y movilidad; pero, ¿en cuáles de las perfecciones de Dios veo esta esencia?» (Locke, 1991a: 79). «No ha de negarse que Dios puede iluminar nuestra mente conforme a mil maneras diferentes y tampoco puede negarse que esas mil maneras diferentes puedan ser tales que no comprendamos ninguna de ellas»(Locke, 1991a: 55).

16 «El P. Malebranche dice, «Dios hace todas las cosas por los caminos más simples y cortos», esto es, tal como se interpreta en Reason and Religion del Sr. Norris, «Dios nunca hace nada en vano». Esto fácilmente se les concederá, pero ¿cómo reconciliarán con este principio suyo, sobre el que se construye todo su sistema, las curiosas estructuras del ojo y del oído, para no mencionar las otras partes del cuerpo?» (Locke, 1991a: 85). 
conocimientos útiles si, después de haber descubierto hasta dónde tenemos ideas claras y distintas, restringimos nuestros pensamientos dentro de los límites de la contemplación de aquellas cosas que estén al alcance de nuestro entendimiento, y no nos lanzamos en aquel abismo de tinieblas (en que no tenemos ojos para ver, ni facultades para percibir), impulsados por la vanidad de que nada está más allá de nuestra comprensión (Essay, IV, III §1).

El carácter limitado y falible de nuestro conocimiento debe conducir a una actitud humilde y tolerante en materia de fe. Este escepticismo se halla muy lejos de la posible geometría moral de otros pasajes (Essay, IV, III, §1; véase también IV, III, §18; IV, IV, §6; I, IV, §1, §4; IV, V, §11, IV, XII, §8; ELN, 2007: 26-28; EMO, 1991b: 93). Lo cierto es que sí fuera posible establecer una geometría moral, aún así no sería deseable un canon universal en materia de fe, por sus impacto negativo sobre la convivencia pacífica entre los hombres.

De este modo, es posible trazar una línea de continuidad en la argumentación lockeana entre la necesidad de una crítica racional de la fe, esto es, su dimensión latitudinaria, y un escepticismo (Shapiro, 1968: 38, 29-30, 35, 19) que deriva a su vez en un concepto, por cierto muy limitado, de tolerancia. En efecto, la interpretación de Locke acerca de la racionalidad de las Escrituras, no es neutral ni pretende serlo. Locke se reconoce como protestante ${ }^{17}$ y critica de modo explícitamente intolerante a los católicos: «[...] una iglesia cuyos individuos todos, desde el momento de entrar en ella, pasan, ipso facto, al servicio y la dominación de otro príncipe, no tiene derecho ninguno a ser tolerada por el magistrado» en cuanto, de hacerlo, ello permitiría «que se valieran de sus súbditos para hacerle la guerra» ( $L, 1999$ : 142; véase también 141; véase también Gough, 1964: 45-46; Shapiro, 1968: 36; Amor, 2006: 257-271). En este sentido, su crítica al catolicismo se halla en sintonía con el rechazo de $E L N$ a la adquisición de la ley moral por tradición ( $E L N, 2007: 22$; véase 40).

Tómese un católico-romano inteligente, a quien se le haya constantemente inculcado, desde el primer amanecer de su entendimiento, este principio, a saber: que está obligado a creer lo que cree la Iglesia (es decir, los de su propia comunión), o que el Papa es infalible, de suerte que jamás haya oído que nadie ponga eso en tela de juicio, hasta que, llegado a la edad de cuarenta o cincuenta años, descubra otro hombre que abrigue unos principios diferentes. ¿En qué fácil disposición

17 En «John Locke on the Glorious Revolution»(GR, manuscrito de 1690 posterior a la Revolución Gloriosa, publicado por James Farr y Clayton Roberts y traducido bajo el título de «De la lealtad y la resistencia» por Blanca Rodríguez López y Diego A. Fernández Peychaux), Locke expresamente se autodenomina «amante de la paz y del interés Protestante» (GR, 2011: 168) y acusa al papado de provocar sedición (GR, 2011: 171: véase también 172-173, 176). 
no estará de tragarse, no sólo contra toda probabilidad, sino aún contra la clara evidencia de sus sentidos, la doctrina de la transubstanciación? Ese principio tiene tal influencia sobre su mente, que creerá que es carne aquello que sus ojos le dicen ser pan (Essay, IV, XX, §10; Shapiro, 1968: $\left.36^{18}\right)^{19}$.

El problema de esta crítica, típicamente protestante, es que atenta contra la autoridad de las Escrituras, anteriormente invocada y aceptada, como transmisora de la palabra de Dios (Essay, IV, XIX, §16 $20 ; T T$, I, §39²1; $R, 1977$ : $248-249^{22}$, véase también 227, 229). Entiéndase: en este pasaje Locke se permite cuestionar, a partir de la razón individual, la verosimilitud de los dichos del propio Jesús durante la última cena, tal como la retratan los Evangelios, precisamente por resultar contrariar la experiencia común y el curso ordinario de las cosas (Essay, IV, XVI, §14). Aquí, en efecto, Locke no encuentra problemático o intolerante atribuirse un conocimiento racional de las Escrituras contra ciertas

18 Para una interpretación y justificación histórica del anti-catolicismo lockeano, véase Tully, 1980: 53; también, Dunn, 1969: 43-57.

19 Si aquí la tradición, al igual que en $E L N$, es asociada a la ceguera de los católicos, en $R$ reconoce la posibilidad de conocer primero la ley de naturaleza por la tradición: «Muchos, que no lo reconocen, tienen deudas con la revelación. No es empequeñecer la revelación el que la razón también dé su sufragio a las verdades que aquélla ha descubierto. Pero es nuestra equivocación pensar que, porque la razón nos las confirma, tuvimos por ella el primer conocimiento cierto de ellas y que en esa clara evidencia las poseemos ahora» $(R, 1977: 232)$.

20 «Allí donde la verdad que abrazamos se halla conforme a la palabra escrita de Dios, allí donde la acción que meditamos no se opone a los dictados de la recta razón y de las Sagradas Letras, podemos estar seguros de que no corremos ningún riesgo en considerarlas como inspiraciones divinas [ ]. Nada puede hacer eso, salvo la palabra escrita de Dios (que es exterior a nosotros) o aquella norma racional que nos es común con todos los otros hombres. Donde la razón o la Escritura autoricen expresamente alguna opinión o algún acto, podemos recibirlos como de autoridad divina» (Essay, IV, XIX, §16).

21 «En vuestras manos son entregados, dice Dios a Noé y sus hijos [...]» (TT, I, §39). «Todas las cosas movientes que viven -dice Dios- serán alimento para ti; lo cual no le fue permitido a Adán en su privilegio» (TT, I, §39).

22 Jesús, acorde con el testimonio bíblico: «[...] declaró a toda la humanidad que quien quiera que crea que él es el Salvador prometido y le acepte ahora resucitado de entre los muertos y constituido Señor y Juez de todos los hombres para ser su Rey y Soberano, sería salvado. Esta es una proposición sencilla e inteligible; el Dios misericordioso parece con esto haber tenido en cuenta a los pobres de este mundo y a la masa de la humanidad. [...] Los escritores y polemistas en materia de religión la llenan de sutilezas y la adornan con ideas que hacen partes necesarias y fundamentales de ella, como si no hubiera otro camino hacia la iglesia sino a través de la Academia o del Liceo. La mayoría de la humanidad no tiene tiempo libre para el saber y la lógica y las distinciones sutiles de las escuelas» $(R, 1977: 248-249$, véase también 227, 229). 
vías tradicionales de enseñanza religiosa, explicando sus creencias por mera repetición habitual de ideas (Essay, II, XXXIII, §§17-18) ${ }^{23}$.

El carácter selectivo del uso de las Escrituras se advierte también, indirectamente, en la propuesta de educación de los niños que serán futuros caballeros. En efecto, Locke rechaza, en parte por tratarse de historias difíciles de entender para los niños, pero también por su contenido fantástico y la invocación de espíritus malignos, reconociendo de este modo el carácter irracional de ciertos pasajes bíblicos (Education ${ }^{24}, 1880$ : §138; §158, §190).

A este efecto deduzco que será conveniente hacer leer a los niños una buena Historia Sagrada, en al que se clasifiquen, según el orden exacto de los tiempos, todas las cosas que sea conveniente hacer entrar en ella, omitiendo las que no convienen sino para una edad más avanzada; se evitará así la confusión que se produce en el espíritu cuando se leen indistintamente todos los libros de la Escritura tales como están reunidos en la Biblia (Education, 1880, §190). [...] sólo que hay inconvenientes en hacer entrar en su pensamiento estas imágenes de fantasmas, de espectros, de apariciones fantásticas, que los preceptores y todos los que rodean a los niños les presentan para asustarlos y asegurarse de su obediencia. Esta es una falta de la que los niños sufren durante toda su vida, porque esclaviza sus espíritus, ante temores y aprensiones terribles, a la debilidad y a la superstición (Education, 1880, §191; véase también \$138, §158).

Como se ve, Locke considera que la lectura de determinados pasajes bíblicos desarrolla la fantasía, la superstición y esclaviza el espíritu, por lo que mejor es omitirlos y reescribir las historias bíblicas sin ellos. Esta dimensión selectiva es presentada a su vez en Of Ethics in General, al plantear la necesidad de separar la moralidad de toda forma ritual propia de un pueblo particular $\left(E G^{25}\right.$, 2011: 157-159; véase también Gaela Esperanza, 2006: 75). Se trata, como hemos destacado ya, de una operación propia del latitudinarismo: «Una de las aproximaciones básicas de los latitudinaristas era la distinción entre los fundamentos y las cuestiones no esenciales de la religión. El énfasis en aspec-

23 Lo mismo hemos visto que se aplica a los paganos que se referían a la otra vida de modo supersticioso, a diferencia de la verdadera iglesia cristiana: «Si el sacerdote hablaba alguna vez de los espíritus inferiores y de una vida después de ésta, era sólo para mantener a los hombres en sus ritos supersticiosos e idólatras; por ello la utilidad de esta doctrina se perdió para la multitud creyente y su creencia para los más inteligentes, quienes sospecharon en seguida que era artificio de los sacerdotes. Antes del tiempo de nuestro Salvador, la doctrina de un estado futuro, aunque no escondida del todo, sin embargo, no era conocida claramente en el mundo» $(R, 1977: 238)$.

24 Some Thougths Concerning Education. Usaremos en todos los casos la edición castellana, traducida por Domingo Barnés.

25 Of Ethics in General. Usaremos en todos los casos la edición castellana, traducida por Blanca Rodríguez López y Diego A. Fernández Peychaux. 
tos no esenciales como las ceremonias, las doctrinas oscuras, los requisitos de atuendo y las formas de plegaria era reducido» (Shapiro, 1968: 37). En este sentido, son varios los elementos de la descripción de Shapiro que se aplican a la obra de Locke: la necesidad del carácter público de los cultos religiosos, la tolerancia a las diversas sectas (protestantes), la posibilidad de error, la actitud científica, el lenguaje llano (Shapiro, 1968: 29-30, 32, 34) ${ }^{26}$. «Otro elemento en el pensamiento latitudinario que separa a sus partidarios de la mayoría de los puritanos es el gran énfasis en los aspectos morales de la religión. Las cuestiones doctrinales fueron empujadas a un segundo plano en virtud de enfocarse en los elementos morales del cristianismo y los fundamentos de la religión» (Shapiro, 1968: 31). En efecto, como bien señala Aaron, para Locke «el credo cristiano consistía en unos pocos elementos esenciales (los cuales incluso podrían ser reducidos a uno, que Cristo es el Salvador), y un gran numero de elementos no esenciales» (Aaron, 1965: 29; véase también 27, 39).

Es claro por tanto que a fin de establecer la racionalidad de su interpretación del cristianismo, Locke no puede aceptar todas las proposiciones de las Escrituras. Ello conduciría, por ejemplo, a confundir judaísmo y cristianismo, o a aceptar el principio del derecho divino de los reyes o, cuanto menos, un criterio de obediencia absoluta a los reyes, muy patente en el Antiguo Testamento (I, Sam. Viii, 11, 12, \&c.; Hobbes, 1999, XX: $184^{27}$ ). Por lo tanto, invocando el

26 La interpretación de Shapiro es especialmente importante porque reafirma nuestra asociación entre latitudinarismo y protestantismo al interior del pensamiento lockeano. En efecto, en el caso de Locke se aplica especialmente la actitud ecuménica de tolerancia entre las diversas sectas protestantes. Como bien señala Shapiro, debe relativizarse el antagonismo entre puritanos y anglicanos. Como bien señala este intérprete, muchas veces ambos compartían las mismas creencias y en otras ocasiones los miembros de una secta dejaban de practicar su culto para practicar el otro (Shapiro, 1968: 16-19). Este espíritu de aceptación general al interior del protestantismo, constituye una decisión estratégica de Locke, y en este sentido debemos entender el concepto de tolerancia. En efecto, es en virtud de una vaguedad deliberada que Locke no ha establecido ni pretendido establecer una adscripción propia más específica a una secta particular del protestantismo.

27 «Dios mismo dice por boca de Samuel (1 Samuel viii. 11, 12, etc.): Ved cómo os tratará el rey que reinará sobre vosotros: Tomará a vuestros hijos y los pondrá sobre sus carros y entre sus aurigas y los hará correr delante de su carro; les hará recolectar sus mieses, fabricar sus armas de guerra y el atalaje de sus carros. Tomará a vuestras hijas para perfumeras, cocineras y panaderas. Tomará vuestros mejores campos, viñas y olivares y se los dará a sus servidores. Diezmará vuestras cosechas y vuestros vinos para eunucos y servidores. Tomará vuestros siervos y vuestras siervas, y lo mejor de vuestra juventud para emplearlos en sus obras. Diezmará vuestros rebaños, y vosotros mismos seréis siervos suyos. Esto es el poder absoluto, que queda resumido en las últimas palabras: serésis siervos suyos. [...]. Saúl quería quitar la vida a David; sin embargo, cuando estuvo en manos de éste matar a Saúl, cosa que sus siervos podrían haber hecho, David se lo prohibió diciendo (1, Samuel XXIV. 9): Dios prohíbe que yo realice un acto así contra mi señor, el ungido de Dios. [...] Y vemos en San Pablo (Tito III, 1): Adviérteles que vivan sumisos a los príncipes y a las autoridades, y que las obedezcan. [....] Por último, nuestro mismo Salvador admite que los hombres deben pagar las tasas que impongan los reyes, cuando 
universalismo cristiano, Locke intentará reducir el cristianismo a una moralidad simple y tolerante, que, por ejemplo, no niegue la posibilidad de salvación de las almas a aquellos que no hayan recibido el testimonio escrito de la palabra divina $^{28}$. Fundamentalmente, sin embargo, intentará negar el derecho divino de los reyes a un dominio privado y político sobre los hombres por nacimiento (TT, I, §§23-24, §32-39), y descartar lo que, según él, no puede considerarse racionalmente como necesario para la salvación de las almas.

[...] supuesto que cuesta tanta dificultad el saber cuál es la verdadera iglesia, preguntaré solamente aquí, de paso, si no se conforma más con el carácter de la iglesia de Jesucristo el exigir por condiciones de comunión las únicas cosas que la Santa Escritura declara en términos expresos como necesarias para la salvación, que el imponer sus propias invenciones o explicaciones particulares a los otros, como si estuvieran apoyadas sobre una autoridad divina, y establecer con leyes eclesiásticas, como absolutamente necesarias a la profesión del cristianismo, cosas de las que la Escritura no dice ni una palabra, o al menos que ella no prescribe en términos claros y positivos $(L, 1999$ : 116-117).

La impronta protestante es aquí tan marcada que vuelve innecesario un mayor desarrollo al respecto. Partiendo entonces de la oscuridad o el carácter no expreso de infinidad de pasajes de las Escrituras, Locke se autoriza a establecer un criterio declaradamente selectivo. Ahora bien, resulta fundamental evitar la construcción de un nuevo gran canon eclesiástico. Por lo que es preciso reducir la esencia del cristianismo a un conjunto simple de sus premisas fundamentales.

dice: Dad al César lo que es del César» (Hobbes, 1999, XX: 184).

28 «La objeción común aquí es que si todos los pecadores serán condenados, a excepción de aquellos a quienes se les hace una concesión gratuita, por la cual Dios los justifica al creer que Jesús es el Mesías y aceptarle como su Rey, a quien están decididos a obedecer hasta el límite de su poder, ¿qué será de toda la humanidad, que vivió antes del tiempo de nuestro Salvador, que nunca oyó su nombre y, en consecuencia, no podía creer en él? La contestación a esto es tan evidente y natural que uno se pregunta cómo un hombre razonable puede considerar que valga la pena insistir en ella. A nadie se le requeriría, ni se le puede requerir, creer lo que nunca se le propuso para ser creído» $(R$, 1977: 207-208). «[...] yo deseo que aquellos que nos dicen que Dios no aceptará (más aún, algunos llegan a decir que no puede aceptar) a nadie que no crea cada artículo de sus doctrinas y sistemas particulares, consideren: ¿por qué Dios, en su misericordia infinita, no puede ahora también justificar a los hombres por creer que Jesús de Nazaret es el Mesías prometido, el Rey y Libertador, como hizo con aquellos de antes, que sólo creían que Dios, según su promesa, enviaría al Mesías, en su tiempo debido, para ser un Rey un Libertador? $(R, 1977: 212)$. «[...] ¿qué pasará con el resto de la humanidad, que, no habiendo jamás oído de la promesa o la noticia de un Salvador, ni una palabra de un Mesías que sería enviado o que había venido, no tenía ni idea ni creencia respecto a él?» A esto contesto que Dios requerirá de cada hombres «según lo que tiene, y no según lo que no tenga» $(R, 1977: 213)$. 
Aunque toda la revelación divina requiere la obediencia de la fe, sin embargo, cada verdad de las Escrituras inspiradas no es de aquellas que por la ley de la fe se requiere que se crea explícitamente para la justificación. Cuáles son aquéllas lo hemos visto por lo que nuestro Salvador y sus apóstoles propusieron y exigieron de aquellos que convirtieron a la fe. Son fundamentales aquellas en que no es bastante no desconfiar y se requiere que cada uno las consienta de hecho. Pero cualquier otra proposición contenida en las Escrituras, que Dios no ha hecho así una parte necesaria de la ley de la fe (sin consentimiento a la cual no admitirá a nadie como creyente), un hombre puede ignorarla sin arriesgar su salvación por un defecto en la fe. [...] Donde, después de esfuerzos razonables, no lo entiende, ¿cómo puede evitar ser ignorante? Y donde no puede poner varios textos y hacerlos permanecer juntos, ¿qué alternativa hay? O tiene que interpretarlos uno por uno, o suspender su opinión. [ ] Dios, por la infinitud de su misericordia, ha tratado al hombre como un Padre compasivo y tierno. Le dio la razón y con ella una ley, que no podía ser de otra manera que como la razón dictara, a menos que pensáramos que un ser razonable tuviera una ley irracional ( $R, 1977: 247-248)$.

Esta operación selectiva resulta particularmente importante para distinguir entre los mandamientos de Moisés, aquellos que son considerados parte del derecho natural, y por tanto obligatorios para todos los hombres, de aquellos mandatos considerados como parte del derecho positivo del Estado israelí, y por tanto no obligatorio para los cristianos.

[...] la parte civil y ritual de la ley entregada por Moisés, no obliga a los cristianos, aunque para los judíos sea parte de la ley de obras, siendo una parte de la ley de la naturaleza que el hombre debía obedecer cada ley positiva de Dios, siempre que le plazca hacer tal adición a la ley de su naturaleza; pero la parte moral de la ley de Moisés, o la ley moral (que es en todas partes la misma, la regla eterna de justicia), obliga a los cristianos y a todos los hombres en todos los lugares, y es para todos los hombres al ley de obras establecida ( $R, 1977$ : 66-67; véase también 64).

En efecto, para que sea posible el tipo de Estado que Locke tiene en mente, es preciso desligarse del supuesto derecho positivo de Israel y, fundamentalmente, eludir de este modo su carácter teocrático, que Locke atribuye al judaísmo, y pretende deslindar del cristianismo. La estrategia de Locke es aquí separar derecho positivo de derecho natural con el fin de evitar tomar por cristiano al modelo teocrático del Antiguo Testamento: «la república de los Judíos, muy diferente en esto de todas las demás, era una mera teocracia [ ]. Pero, bajo el imperio del Evangelio, no hay, en rigor, república cristiana ninguna» ( $L, 1999$ : 135). El cristianismo, a diferencia del judaísmo se caracteriza por evitar el gobierno político de los hombres en este mundo: «Jesucristo no dio mandato ninguno absolutamente. Contento con enseñar a los hombres cómo pueden por 
medio de la fe y buenas obras alcanzar la vida eterna, no instituyó ninguna especie de gobierno, ni armó al magistrado con la cuchilla» $(L, 1999: 135)$. Locke separa así toda articulación entre mandato divino y gobierno político, reduciendo la esencia moral del Antiguo Testamento a los diez mandamientos.

El cristianismo toma del judaísmo la ley de las obras, la cual exige, como toda ley, una obediencia perfecta: «sin ninguna relajación ni reducción» $(R$, 1977: 63). Como principio de justicia, la ley de las obras del Antiguo Testamento no da un lugar privilegiado a la fe $(R, 1977: 63)$. Sólo a partir del Nuevo Testamento surge la ley de la fe, la cual consiste en ofrecer la redención a aquellos que crean que Jesús es el Mesías. Por medio de esta ley, Locke establece la esencia del cristianismo, relegando así una infinidad de elementos bíblicas, que carecerán de este status privilegiado (González Puertas en $R$, 1977: 37). En efecto, según Locke el cristianismo se caracteriza, a diferencia del judaísmo, por estar destinado no a los justos que cumplen con la ley de las obras, sino a los pecadores, buscando su arrepentimiento: «Y (Lc 5,32) dice a los escribas y fariseos: «No he venido yo a llamar a los justos» (los que lo eran verdaderamente no necesitaban ayuda, tenían derecho al árbol de la vida) «sino a los pecadores en penitencia» $(R, 1977: 191)$.

La ley de la fe, sin embargo, no invalida la vigencia de los mandamientos ni su obligatoriedad, sino que, por el contrario establece un mecanismo para expandir su aplicación real y concreta. Con un criterio consecuencialista, la ley de la fe intenta maximizar la vigencia práctica de la ley de las obras. Para ello, es preciso incorporar este mecanismo de perdón y arrepentimiento: «[...] los creyentes cristianos tienen el privilegio de estar también bajo la ley de la fe, que es la ley mediante la cual Dios justifica al hombre por creer, aunque por sus obras no sea justo ni recto, i. e., aunque falte en obediencia perfecta a la ley de obras» $(R, 1977: 67)$. Ahora bien, esto no significa que la sola creencia en que Jesús es el Mesías y regresará a juzgar a las almas, sea suficiente para la salvación (Yolton, 1958: 485). El requisito aquí es el sincero arrepentimiento que reencamine la conducta de los díscolos. En efecto, no apunta aquellos que creen que Jesús es el Mesías pero no tienen intención de cumplir con la ley de las obras: «porque una fe como ésta la pueden tener los diablos y es claro que la tenían, pues creyeron y declararon «que Jesús era el Mesías». Y Santiago $(2,19)$ nos dice: «Los demonios creen y tiemblan»; sin embargo, no se salvarán» $(R$, 1977: 176). En efecto, la ley de la fe no puede ponerse en contradicción con la ley de las obras. «El arrepentimiento es una condición tan absoluta del pacto de gracia como la fe, y tan necesario como ésta para ser cumplido» $(R, 1977$ : 177; véase también 187, 201).

La racionalidad del cristianismo es por tanto práctica: se sustenta en el mejoramiento moral de la humanidad en sentido concreto. En este sentido se entiende que el cristianismo sea una religión sencilla, orientada a la mayoría 
de los hombres, que eran pobres y pecadores. «Cristo hace del que a los pobres se les predique el Evangelio un signo, además de un oficio, de su misión (Mt 11,5). Y si a los pobres se les predicó el Evangelio, era sin duda un Evangelio tal como los pobres podían comprender: sencillo e inteligible» $(R, 1977: 250)$. Es precisamente la practicidad y la lógica utilitaria, de las consecuencias, la que permite justificar el perdón. Ahora bien, la objeción que nace naturalmente es ¿cómo esta lógica evita caer en la excepcionalidad permanente? Pues, según los Evangelios la gracia no es simplemente concedida en una oportunidad sino indefinidamente: «(Ver. 21): «Pedro le preguntó: Señor, ¿cuántas veces he de perdonar a mi hermano si peca contra mí? ¿Hasta siete veces? Dícele Jesús: No digo yo hasta siete veces, sino hasta setenta veces siete»" $(R, 1977: 194)$. Locke explica los beneficios de esta laxitud:

[...] la rectitud u obediencia a la ley de Dios era su gran preocupación, la cual, si la hubieran podido conseguir por sus propias acciones, no hubiera hecho falta esta concesión gratuita en recompensa de su fe, pues la vida eterna, después de la resurrección, les había correspondido por un pacto anterior, el de obras, cuya regla nunca fue abolida, aunque se moderó su dureza. Los deberes ordenados en ella seguían siendo deberes $(R, 1977: 200)$.

El perdón es en primer lugar una necesidad: hay infinidad de pecadores y debe buscarse su salvación. En segundo término, es una actitud tolerante, pues todos los hombres pecan. «(Mt 6,14): «si no perdonáis a los hombres, tampoco vuestro Padre perdonará vuestras ofensas» $(R, 1977: 201)$. En ambos casos se trata de un principio de realidad y de voluntad de mejoramiento. Antes que explicar cómo la ley de la fe y de la gracia no lleva a una excesiva permisividad, Locke se ocupa de señalar que, en caso contrario, la religión no hace ninguna contribución al estado de hecho del mundo ${ }^{29}$.

29 «En verdad que no esperaba una obediencia perfecta, sin lapsos ni caídas; conocía demasiado bien nuestro modo de ser, la debilidad de nuestra constitución, y era enviado para suplir ese defecto. Además, la obediencia perfecta es la rectitud de al ley de obras y, entonces, la recompensa sería de deuda y no de gracia; y ésos tales no necesitaban que se les cuente la fe como justicia. Resistían por sí mismos, eran ya justos y no necesitaban ninguna concesión por creer que Jesús era el Mesías, recibirle como su rey y hacerse súbditos. Pero que Cristo requiere obediencia, obediencia sincera, es evidente por la ley que él mismo establece [ ] y por la sentencia que pronunciará cuando venga a juzgar» $(R, 1977: 189)$. «(Ver. 21): «Pedro le preguntó: Señor, ¿cuántas veces he de perdonar a mi hermano si peca contra mí? ¿Hasta siete veces? Dícele Jesús: No digo yo hasta siete veces, sino hasta setenta veces siete»" $(R, 1977: 194)$. «(Lc 17,3): «Si peca tu hermano contra ti, corrígele, y si se arrepiente, perdónale. Si siete ves al día peca contra ti y siete veces se vuelve a ti diciéndote: Me arrepiento, le perdonarás» $(R, 1977: 196-197)$. «iPor qué me llamáis: Señor, Señor, y no hacéis lo que os digo?», dice él (Lc 6,46). No es bastante con creer que él es el Mesías, el Señor, sino obedecerle" $(R, 1977: 200)$. 


\section{CONCLUSIÓN}

Podemos concluir, por tanto que la definición que Locke realiza del cristianismo, se realiza a través de una selección explícita y deliberada de rasgos protestantes. Hemos visto, al mismo tiempo, cómo esta selección supone cierto escepticismo crítico frente a las Escrituras, el cual habría de conducir a cierta tolerancia en materia de fe. En este sentido, a pesar de servirse de argumentos universalistas, Locke desestima las creencias de los católicos, establece distancias con el judaísmo y propone una fe racional cristiana que se presenta como superadora desde el punto de vista moral respecto a toda otra religión. Se afirma así el carácter latitudinario de la apropiación selectiva de las Escrituras, la cual, a partir de cierto escepticismo moderado, extrae una idea de tolerancia para con las diversas sectas protestantes y el judaísmo, con exclusión de católicos y ateos (L, 1999: 141-142; Gaela Esperanza, 2006: 80).

Existe, de este modo, una articulación entre el carácter racional de la fe, esto es su dimensión latitudinaria, y un escepticismo que deriva en un limitado concepto de tolerancia. En efecto, Locke articula, con un mayor sentido de la estrategia que de la rigurosidad argumental, por una parte las apelaciones a la ignorancia con vistas a la tolerancia y por el otro las apelaciones a la racionalidad de cierta interpretación del cristianismo. Si, por un lado, se plantea la necesidad de cierto escepticismo saludable a fin de evitar la violencia por razones de fe, ello no impide realizar una interpretación particular que establece cuáles son los verdaderos principios fundamentales del cristianismo, como moralidad superior en el mundo.

REFERENCIAS BIBLIOGRÁFICAS

PRIMARIA

LOCKE, J. 1824: Works of John Locke in Nine Volumes. Londres: Rivington.

,1965: Enssays on the law of nature. The latin text with a traslation, introduction and notes, together with transcripts of Locke's shorthand in his journal of 1676 (ed. W. von Leyden). Oxford: Oxford University Press.

—_ _ 1967: Two Tracts on Government (tr. P. Abrams). Cambridge: Cambridge University Press.

___ _ 1977: La racionalidad del cristianismo (tr. Leandro González Puertas). Madrid: Ediciones Paulinas.

, 1978: The correspondence of John Locke (ed. E. S. de Beer). Volume IV. Oxford: Oxford University Press.

, 1991: Examen de la opinión del padre Malebranche de ver todas las cosas en Dios. En Obras varias y correspondencia de (y sobre) John Locke (tr. José 
Antonio Robles y Carmen Silva). México: Universidad Autónoma Metropolitana, pp. 35-81.

___ _ 1999: «Carta sobre la tolerancia» en Escritos sobre la tolerancia (tr. L. Prieto Sanchís y J. Betegón Carrillo). Madrid: Centro de estudios políticos y constitucionales, pp. 107-151.

___ 2004: Two Treatises of Government (tr. Peter Laslett). Cambridge: Cambridge University Press.

____ 2007: La Ley de la Naturaleza (tr. Carlos Mellizo). Madrid: Tecnos.

-, 2011: «De la Ética en general» en Ensayo sobre la tolerancia y otros escritos sobre ética y obediencia civil (tr. Blanca Rodríguez López y Diego A. Fernández Peychaux). Madrid: Minerva, pp. 155-165.

_, 2011: «De la lealtad y la resistencia». en Ensayo sobre la tolerancia y otros escritos sobre ética y obediencia civil (tr. Blanca Rodríguez López y Diego A. Fernández Peychaux). Madrid: Minerva, pp. 167-176.

\section{SECUNDARIA}

AARON, R. 1965: John Locke. London: Oxford University Press.

AARSLEFF, H. 1969: «The state of nature and the nature of man in Locke». En Yolton, John W. (ed.). John Locke: Problems and Perspectives. Cambridge: Cambridge University Press, pp. 99-136.

ASHCRAFT, R. 1968: «Locke's State of Nature. Historical fact or Moral Fiction?». The American Political Science Review. Vol. LXII, N 3, pp. 898-915.

CHUMBITA, J. S. 2011: «El desplazamiento en la teoría de la propiedad de John Locke: del criterio de necesidad a la teoría del valor para justificar la colonización inglesa en América». Cuyo: Anuario de filosofía Argentina y Americana. Vol. 28, pp. 93-120.

- 2013a: «Un análisis de las nociones de abundancia y esclavitud para reinterpretar el carácter universal de la teoría de la apropiación de John Locke». Las torres de Lucca. $\mathrm{N}^{\circ} 2$. Enero-junio, pp. 69-83.

___ 2 2013b: «La caridad como administración de la pobreza». Identidades. Revista del Instituto de Estudios Sociales y Políticos de la Patagonia. № 4. Junio, pp. 1-21.

, 2013c: «Apropiación privada de la tierra y derechos políticos en la obra de John Locke». Ingenium. Revista de historia del pensamiento moderno. $\mathrm{N}^{\circ} 7$, pp. 193-210.

2014a: «Teología política, libertad natural, paz relativa y secularización en el estado de naturaleza descrito por John Locke». Bajo palabra. № 9. Septiembre (en prensa).

___ 2014b: «La resistencia social como configuración del pueblo según John Locke». Revista SAAP. Vol. 8. № 1 (en prensa).

__— $2014 \mathrm{c}$ : «Actores sociales y económicos en las propuestas jurídicas y 
normativas de John Locke». Anales del Seminario de Historia de la Filosofía. Vol. 31. $\mathrm{N}^{\circ} 1$ (en prensa).

DUNN, J. 1969: The political thought of John Locke. An historical account of the argument of the "Two Treatises of gobernment». Cambridge: Cambridge University Presss.

FARR, J. Y ROBERTS, C. 1985: «John Locke on the Glorious Revolution: a rediscovered document». The Historical Journal. Vol. 28. N 2, pp. 385-398.

FILMER, Sir R. 1966: Patriarcha en La polémica Filmer-Locke sobre la obediencia política. Madrid: Instituto de estudios políticos.

GAELA ESPERANZA, J. 2006: John Locke and the Natural Law. Yesterday and Today: a critical analysis. Extracto de Tesis Doctoral. Pamplona. Facultad Eclesiástica de Filosofía. Universidad de Navarra.

GOUGH, J. W. 1964: John Locke's Political Philosophy. Oxford: Oxford University Press.

HALL, R. 1981: John Locke and Natural Human Rights: an Inconsistency between his metaphysical/epistemological positions and his moral/political theories. Michigan: University Microfilms International.

HANCEY, J. O. 1976: «John Locke and the Law of Nature». Political Theory. Vol. 4. $\mathrm{N}^{\circ}$ 4. Nov., pp. 439-454.

HOBBES, T. 1999: Leviatán (tr. Mellizo). Buenos Aires: Alianza.

LENZ, J. W. 1956: «Locke's Essays on the Law of nature». Philosophy and Phenomenological Research. Vol. 17. № 1. Sep., pp. 105-113.

LEYDEN, W. Von. 1965: «Introduction». En Enssays on the law of nature. The latin text with a traslation, introduction and notes, together with transcripts of Locke's shorthand in his journal of 1676. Oxford: University Press Oxford.

SELIGER, M. 1963: «Locke's Natural Law and the Foundation of Politics». Journal of the History of Ideas. Vol. 24. No. 3, pp. 337-354.

SHAPIRO, B. J. 1968: «Latitudinarianism and Science in Seventheenth-Century England». Past \& Present. $\mathrm{N}^{\circ}$ 40. Jul., pp. 16-41.

SINGH, R. 1961: «John Locke and the Theory of Natural Law». Political Studies. Vol. IX. N², pp. 105-118.

SIMMONS, A. 1992: The lockean theory of rights. Princenton: Princenton University Press.

STRAUSS, L. 1992: Natural Right and History. Chicago: Chicago University Press.

WALDRON, J. 2002: God, Locke and Equality: Christian Foundations in Locke's Political Thougth. Cambridge: University Press Cambridge.

YOLTON, J. W. 1958: «Locke on the Law of Nature», The philosophical Review, vol. 67, $\mathrm{N}^{\circ}$ 4. Oct., pp. 477-498. 
Joan Severo Chumbita. es doctorando en Filosofía (UBA). Máster en Ciencias Políticas (IDAES-UNSAM), Magistrando en Sociología Económica (IDAES-UNSAM). Docente auxiliar en la cátedra de Ética, en el Departamento de Filosofía, Facultad de Filosofía y Letras, UBA. Becario doctoral del Conicet. Miembro del proyecto de investigación UBACyT «La noción de política en el pensamiento de Giorgio Agamben, Roberto Esposito y Antonio Negri» dirigido por el Dr. Marcelo Sergio Raffin, correspondiente al área de Sociología, Programación científica 2012-2015, de la Facultad de Ciencias Sociales de la UBA.

\section{Publicaciones:}

- Actores sociales y económicos en las propuestas jurídicas y normativas de John Locke», Anales del Seminario de Historia de la Filosofía, Vol. 31, N 1, 2014 (en prensa).

- «Apropiación privada de la tierra y derechos políticos en la obra de John Locke», Ingenium. Revista electrónica de pensamiento moderno y metodología en historia de las ideas, Vol. 7, 2013c, pp. 193-210.

Correo electrónico: joanchumbita@gmail.com 